\title{
A Review of Field Corrosion Control and Monitoring Techniques of the Upstream Oil and Gas Pipelines
}

\author{
E. S. Ameh ${ }^{1 *}$, S. C. Ikpeseni ${ }^{2}$, L.S. Lawal ${ }^{1}$ \\ ${ }^{1}$ Department of Mechanical Integrity Group, Chevron Nigeria Limited, Delta State, Nigeria. \\ ${ }^{2}$ Department of Mechanical Engineering, Delta State University, Nigeria.
}

\begin{abstract}
All steel pipelines used in hydrocarbon transportation are susceptible to either electrolytic or galvanic corrosion attack which deteriorate with time leading to failure even before end of design life. Consequences of corrosion attack and eventual failure of pipelines within oil and gas industry has been classified into economic, health, safety and environmental impacts. The present study considers detailed review of practical field corrosion control and monitoring mechanisms necessary to preserve, extend service life of pipelines and reduce corrosion impacts. The corrosion controls are various preventive strategies considered during construction and prior to pipelines' commissioning which include design, material selection, protective coating, chemical treatment and cathodic protection system. But the corrosion monitoring strategy is aimed at establishing condition of pipelines and environmental variables that may accelerate corrosion process and this includes potential survey, bacteria count, corrosion coupons and intelligent pigging. The identified corrosion control and monitoring techniques are not governed by any industry code and standard but has been generally accepted as best practice within the oil and gas industry as ways of combating corrosion and evaluating pipelines condition. Therefore, effective implementation of the identified corrosion control and monitoring strategies would limit corrosion attack and guide pipelines' operators to make informed decision and timely respond to corrosion threat before failures.
\end{abstract}

KEYWORDS: cathodic protection, corrosion mechanism, control and monitoring, pipelines, oil and gas.

[Received June 12 2017; Revised October 12 2017; Accepted November 03 2017]

\section{INTRODUCTION}

In the upstream of oil and gas industry, carbon steel pipelines are used for transporting hydrocarbon from jackets to production platforms and to storage tanks before the products are exported with loading vessels and imported to local refineries through trunk pipelines are considered the safest and cost-effective means of hydrocarbon transportation in large volume over long distance despite high susceptibility to corrosion attack (Ameh and Ikpeseni, 2017).

Total network of pipelines length in the world today for oil and gas transportation from reservoirs, refineries, storage facilities and to final consumers is over 3 million kilometers (Mazraeh and Alnaimi, 2015). The corrosion in the oil and gas industry has tremendously increased overhead cost of pipeline operation due to corroded equipment replacement and damages to adjacent equipment. The economic consequences from corrosion impact include pipelines shutdown for months or days to allow replacement and repair of corroded equipment and components (ASM, 2014).

Rising cases of pipelines leakages and fire explosion due to corrosion attack have been reported in the last two decades (Samimi and Zarinabadi, 2011). In Nigeria, the unintentional hydrocarbon release more often results in explosion and fire leading to facilities damage and fatalities to workers and communities along the right of way owing to poor pipelines corrosion management strategies. Apart from loss of properties and lives, the environmental impact usually causes general discomfort, disruption of normal life, pollution of drinking water and farm land (Aroh et al, 2010). Construction and laying of pipelines are big capital investment project. Therefore, operators and owners of pipelines oftentimes have maintenance management plans in place to extend the operational life of these critical assets (Smith et al, 2010).

Improper maintainability of oil and gas pipelines threaten design reliability, environmental hazard with potential threats to property and life from explosion in rupture or leak cases (Kishawy and Gabbar, 2010). According to Murad (2012), over $40 \%$ of unintentional hydrocarbon release to environment has been attributed to corrosion related problems and pipelines corrosion control and monitoring remained daunting task operators are confronted with in the upstream of oil and gas industry (Birkinshaw et al, 2015).

This article discusses typical pipelines corrosion management strategies and detailed technical control and monitoring onshore and offshore pipelines mechanisms which is generally becoming unwritten standard that major oil and gas companies like Chevron, Shell, Total and ExxonMobil now use to improve reliability and management of pipelines. Adoption of corrosion control and monitoring strategies for pipelines in the upstream of process industry would not only extend life span and provide pipelines true assessment condition to make informed decision but prevent potential premature failures, repair and replacement of corroded parts with associated economic and environmental impacts. 


\section{A. Corrosion Phenomenon}

Corrosion has been defined as a destructive attack on metallic material by undergoing chemical reactions after a period of interaction with the environment (Roberge, 2000).

Corrosion occurrence is premised on two mechanisms, namely electrolytic and galvanic corrosion. The electrolytic corrosion is a direct result of current from external source that enters and leaves a metallic steel through electrolytic medium. While the galvanic corrosion occurs by selfgeneration of current because of coupling two dissimilar metals with different energy levels or potentials.

The metal that eventually corrodes is the one that current leaves via the electrolyte (Bushman, 2012). Corrosion attacks on metal is an electrochemical process (Figure 1) in which current leaves anodic site of structure and re-enters the structure at the cathodic site through electrolyte. The electrochemical reactions at the anode and cathode takes place simultaneously and balances each other to become a neutral reaction (Agarwal et al, 2015).

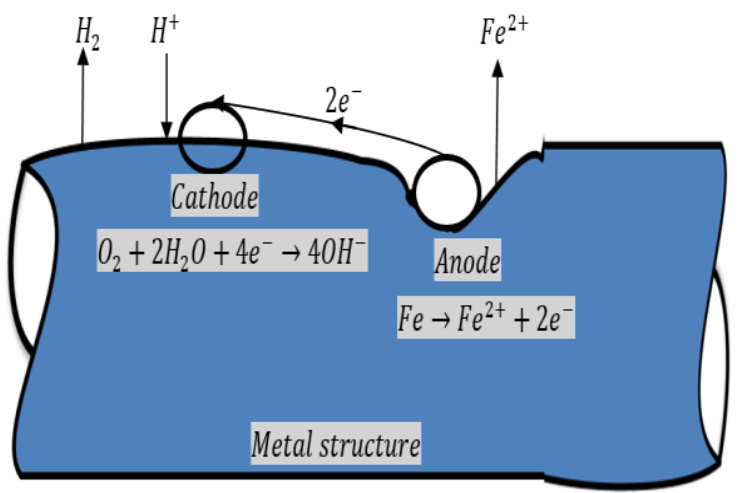

Figure 1: Electrochemical process (Bushman, 2012).

Corrosion takes place in both external and internal surface of pipelines. The external corrosion occurs outside due to interaction of the steel pipelines with the soil or seawater environment leading to current flow from the pipelines to the soil. The rate of current flow may also increase depending on the degree of oxygen concentration differential. But the internal corrosion experiences in pipelines are due to the presence of colonies of bacteria, dissolved carbon dioxide and hydrogen sulfide gases in water. Basically, oil and gas phase itself being transported through pipelines are not corrosive (Cai et al, 2012).

Two types of water are present in the upstream of oil and gas pipelines. These are formation water that comes from the reservoir wells alongside with hydrocarbon and condensate water that forms due to temperature drop below dew point. The water itself is not corrosive but plays significant electrochemical reaction by turning environment acidic when carbon dioxide and hydrogen sulphide present dissolve in water (Samimi, 2012).

Carbon dioxide and hydrogen sulphide corrosion mechanism reactions are written as follow (Xu and Xiaoyu, 2014): $\mathrm{CO}_{2}$ causes local and general corrosion. The local corrosion reaction formula is given as:

$$
\begin{aligned}
& \mathrm{CO}_{2}+\mathrm{H}_{2} \mathrm{O} \rightarrow \mathrm{H}_{2} \mathrm{CO}_{3} \\
& \mathrm{H}_{2} \mathrm{CO}_{3} \rightarrow \mathrm{H}^{+}+\mathrm{HCO}_{3}{ }^{-} \\
& \mathrm{HCO}_{3}{ }^{-} \rightarrow \mathrm{H}^{+}+\mathrm{HCO}_{3}{ }^{2-}
\end{aligned}
$$

$\mathrm{H}_{2} \mathrm{CO}_{3}$ contributes to hydrogen polarization of pipelines:

$$
\mathrm{Fe}+\mathrm{H}_{2} \mathrm{CO}_{3} \rightarrow \mathrm{FeCO}_{3}+\mathrm{H}_{2} \uparrow
$$

But $\mathrm{H}_{2} \mathrm{~S}$ ionizes in the presence of water leading to hydrogen embrittlement:

$$
\begin{aligned}
& \mathrm{H}_{2} \mathrm{~S} \rightarrow \mathrm{H}^{+}+\mathrm{HS}^{-} \\
& \mathrm{HS}^{-} \rightarrow \mathrm{H}^{+}+\mathrm{S}^{2-} \\
& 2 \mathrm{H}^{+}+\mathrm{Fe} \rightarrow \mathrm{Fe}^{2+}+\mathrm{H}_{2} \uparrow
\end{aligned}
$$

$\mathrm{H}_{2} \mathrm{~S}$ also undergo chemical reaction with metal in aerobic environment:

$$
\begin{aligned}
& 2 \mathrm{Fe}+2 \mathrm{H}_{2} \mathrm{~S}+\mathrm{O}_{2} \rightarrow 2 \mathrm{FeS}+2 \mathrm{H}_{2} \mathrm{O} \\
& 4 \mathrm{Fe}+6 \mathrm{H}_{2} \mathrm{~S}+3 \mathrm{O}_{2} \rightarrow 2 \mathrm{Fe}_{2} \mathrm{~S}_{2}+6 \mathrm{H}_{2} \mathrm{O} \\
& \mathrm{H}_{2} \mathrm{~S}+2 \mathrm{O}_{2} \rightarrow \mathrm{H}_{2} \mathrm{SO}_{4} \\
& \mathrm{Fe}+\mathrm{H}_{2} \mathrm{SO}_{4} \rightarrow \mathrm{FeSO}_{4}+\mathrm{H}_{2} \mathrm{O}
\end{aligned}
$$

$\mathrm{H}_{2} \mathrm{SO}_{4}$ in $\mathrm{H}_{2} \mathrm{~S}$ reaction product contributes to chemical and electrochemical corrosion.

\section{CORROSION CONTROL TECHNIQUES}

Corrosion control mechanism in upstream of oil and gas pipelines are mitigative strategies put in place to eliminate or reduce corrosion attack to prevent pipelines failures and associated consequences such as product loss, environmental pollution and potential accidents. Five control mechanisms namely design, material selection, protective coating, cathodic protection and chemical treatment are necessary to be considered during design and construction of pipelines to minimize corrosion attack (Agarwal et al, 2015).

\section{A. Design}

One of the critical factors considered in corrosion control is design (Diaz, 2001). A well-designed steel pipe extends service life of structure (DNV, 1993). Crevices, threaded joint, steel geometry, sharp edge, welded joint and pipeline fittings such as flanges, valves and pipe supports often becomes soft spot for localized corrosion because of fluid penetration and settlement. Furthermore, these soft spots are either poorly coated because of inaccessibility or susceptibility to coating failure. These factors are contributors to corrosion and should be carefully considered in design phase to limit corrosion (NACE, 2007).

Water drop-out and solid particles may accumulate at the bottom of pipelines and remain there for a long period depending on flow condition, promote corrosion by wetting inner surface and becomes site for bacteria colonies if active bacterial are present. Pipelines are more susceptible to corrosion at slow flow that is below critical velocity than with 
high flow that is above critical velocity. Hence, flow condition should be considered in pipeline design stage to ensure normal operation under turbulent flow condition to mitigate sediment and water deposition (Mosher, 2013).

\section{B. Material Selection}

Material selection is fundamental in engineering design consideration for corrosion mitigation. The material selection component should be based on material behaviour on exposure to environmental condition such as fluid chemistry, water composition, velocity, pressure and temperature including mechanical property requirement. On the other hand, compatibility of materials in flanged connection, union connectors, piping and fittings are practical design issues requiring consideration in material selection to prevent galvanic corrosion that may result from coupling dissimilar metals together (Reinhart, 1975). Selection of corrosion resistance alloy and carbon steel material are based on the sour nature of the fluid. But carbon steel has formed the base material for pipeline transportation because of good mechanical property, availability and low cost despite low resistance to corrosion compared to corrosion resistance alloy materials which are more immune. However, carbon steel with corrosion resistance alloy lining or use of complete corrosion resistance alloy material is more effective and recommended where high rate of corrosion is predicted (Intetech, 2010).

\section{Chemical Treatment}

Chemicals including corrosion inhibitor, oxygen scavenger and biocide are utilized in the oil and gas industry to modify process environment in order to limit and control corrosion process in formation and seawater environments (DNV, 1994). The biocide chemicals are injected into the fluid or water system to eliminate microorganisms like sulphide reduced bacteria that enhance microbiologically influenced corrosion where colonies of microorganisms initiate and accelerate corrosion reaction on the surface of steel pipe (Beech and Sunner, 2004). The oxygen scavengers' chemicals are injected to deoxygenate the water which also promote corrosion process. Furthermore, corrosion inhibitors are injected into pipelines either as continuous injection, slug treatment or batching with pig trains (Lim, 2013). The injected corrosion inhibitors are adsorbed on the inner wall of pipe to form passive film that serves as protective layer and prevent direct contact with fluid or water (Ramesh et al, 2003.)

\section{Protective Coating}

Paint is a mastic or liquefiable product that contains pigment and changes to protective opaque film to substrate upon application. Painting with protective coating remained one of the simplest and primary protective techniques of pipelines (Tezdogan and Demirel, 2014). Coating provides resistance against mushrooms and bacteria in the soil environment that may attack pipelines (Samimi and Zarinabadi, 2011). A coated pipeline prevents external surface area from having direct contact with corrosive surrounding environment and consequently impede the flow of ions through the electrolyte, therefore limiting corrosion (DNV, 1993). But the protective coatings are susceptible to failure particularly during construction and in harsh operational environment. Therefore, Cathodic protection system is used in conjunction with coating to compensate for coating deficiency. Major generic type of coatings used on pipelines nowadays include coal tar enamel, fusion bonded epoxy, two-layer coating that usually consist of fusion bonded epoxy bonded to polypropylene and three-layer coating which consist of fusion bonded epoxy, an adhesive thermoplastic and a polypropylene top coating (Romano et al, 2005). However, coating selection criteria are premised on properties such as resistance to cathodic disbondment, adhesion to pipe surface, resistance to seawater and resistance to soil stress (Kehr et al, 2007).

\section{E. Cathodic Protection System}

Cathodic protection technique is one of the control mechanisms employed in corrosion prevention of pipelines buried in soil or submerged in seawater (Miller et al, 1990). The technique is an electrical method based on the principle of electrochemical process where potential of one metal is lowered to reverse the flow of current and prevent corrosion (Mainier et al, 2014). There are two basic techniques of cathodic protection systems which are impressed current and sacrificial anode which are widely used in corrosion control. In the cathodic protection, external anode is connected to intended structure to be protected and electrical direct current passed through so that all the structure surface areas are incapable of undergoing electrochemical reaction and becomes cathodically polarized. The external anode could be impressed anode which source of direct current comes from an external power source or galvanic anode which generate self-current due to difference in potential between the anode and structure to be protected (Mathiazhagan, 2010).

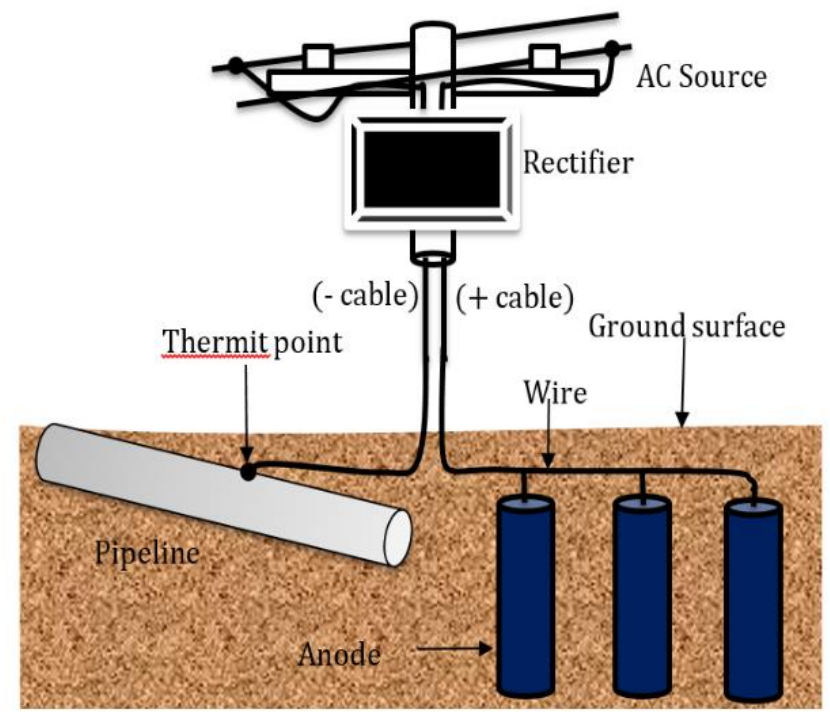

Figure 2: Impressed current system.

The impressed current system (Figure 2) which requires external power source utilizes inert anodes that are connected to rectifier positive terminal while the rectifier power source 
negative terminal is connected to intended structure to be protected. The impressed inert anodes remained non-depleted and undissolved throughout the design life of the impressed system (Bushman, 2012; M'hammed et al, 2014).

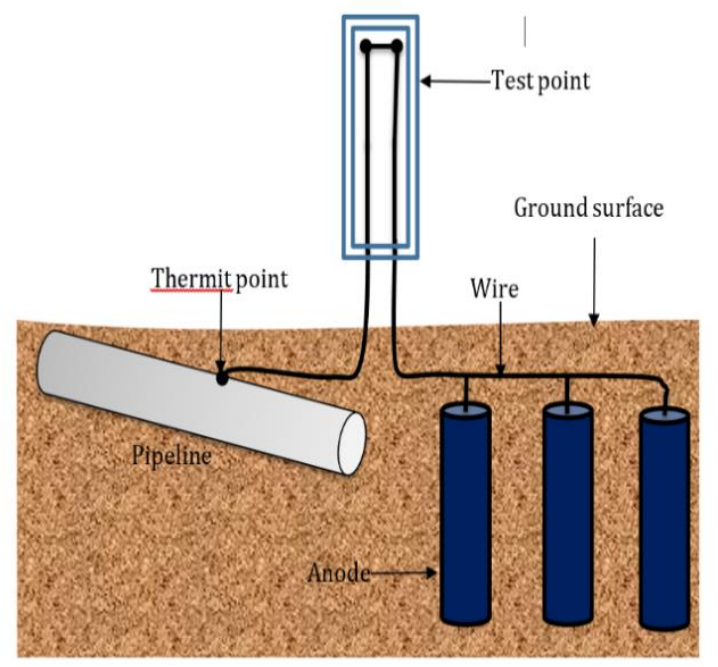

Figure 3: Sacrificial anode system.

For the sacrificial anode system (Figure 3), more negative metallic anodes are connected to intended pipelines through cable wire to achieve complete circuit. The method requires no external power source but the current is generated based on the existing natural potential between protected structure and metallic anodes which dissolve and get depleted gradually during the protection period (Ashworth, 2010; Ezekiel et al, 2015).

\section{CORROSION MONITORING TECHNIQUES}

Corrosion monitoring mechanisms in pipelines are series of activities adopted to monitor condition of pipelines and environment variables that may influence corrosion process and objectively determine if corrosion control mechanisms in place are effective or not. Selection of corrosion monitoring techniques has no governing rule but based on logical decision and effectiveness. Four monitoring practical field techniques namely potential survey, corrosion coupons, bacteria count and intelligent pigging are key requirements to evaluating susceptibility of pipelines to corrosion and make informed decision before failure (Varela et al, 2015; Kjellerup et al, 2006).

\section{A. Potential Survey}

External corrosion monitoring of pipelines is performed with two major techniques known as direct current voltage gradient and close interval potential survey. The direct current voltage gradient involves injection of direct current from temporary source or rectifiers which flow through the soil to coating defect to interrupt source of cathodic protection system and locate coating defect (Nicholson, 2006). Concentric electrical signal potential gradient is usually generated from coating defect present and the voltage gradient increases with increasing coating defect size. The technique involves walking along the entire route of pipeline with two reference electrodes connecting copper wire to rectifier source (Nicholson, 2012). But the close interval potential survey basically measures soil-to-pipe potential of pipelines cathodic protection system level along pipelines route, presence of interaction effect and condition of pipeline coating (Goodland, 2007).

The obtained readings which may include both on and off-instantaneous potentials are assessed in-line with acceptable cathodic protection criteria where a minimum negative potential $850 \mathrm{mV}$ and maximum negative potential $1200 \mathrm{mV}$ is the set standard limit with reference to copper/copper sulfate while a negative potential between $800 \mathrm{mV}$ and $1100 \mathrm{mV}$ is the acceptable threshold with reference to silver/silver chloride electrode. The potentials generated is then used to correlate with tendency of pipelines to corrode. Similarly, in close interval potential survey, voltmeter terminals are connected to reference electrodes and test station and the operator walk along the route of pipeline to take readings at interval of 2 to $3 \mathrm{~m}$ (Peabody, 2001).

\section{B. Corrosion Coupons}

Corrosion coupons is a non-electrochemical monitoring process which involves the use of test coupons of same pipe material has become an effective on-line internal corrosion monitoring method in the upstream of oil and gas industry to monitor corrosion activities and patterns of pipelines internal environment (Oki et al, 2015). The entire surface area of coupons is immersed in a corrosive environment and then taken out for visual inspection, microscopic and weight loss analyses after certain period to obtain corrosion information.

The on-line corrosion coupon technique has been advanced into different forms of probes, which are electrical resistance and inductance probes (Varela et al, 2015). The electrical resistance probes have fitted cross sectional area coupon which corrode with time and the electrical resistance between ends of coupon is measured by probe and increases with coupon corrosion rate. In the case of inductance probe, the working principle is based on eddy current and the probe measures changes in impedance of the magnetic field which increases with increasing weight loss of coupons in corrosive environment ( $\mathrm{Li}$ et al, 2007).

\section{Bacteria Count}

Monitoring of bacteria for bulk water in pipelines forms part of integrity assessment and necessary to identify potential microorganisms, composition of bacteria population density that may promote microbiologically influenced corrosion and bacteria composition that has developed resistance to biocide or grew due to biocide usage (Scott, 2004; Videla and Quintero, 2011). Major type of bacteria organism that accelerate microbial corrosion include sulphate reduce bacteria, carbon dioxide reduces bacteria and manganese-oxidizing reduce bacteria but sulphate reduce bacteria remain the dominant group because of its ability to live in anaerobic environment. The sulphate reduce bacteria can cause severe corrosion attack in pipelines because of their ability to generate enzymes that reduce sulphate compound to 
hydrogen sulphate (Manafi et al, 2013). The other components that need to be monitored in pipelines bulk water in addition to bacteria count include iron count, temperature, PH level, carbon dioxide and hydrogen sulphide.

\section{Intelligent Pigging}

Intelligent pigging is an in-line inspection method use by operators to monitor reliability of pipelines. The inspection tools are called intelligent pigs or smart pigs which are cylindrical in shape and equipped with electronic devices that can locate position or orientation of measured depth and length parameters of metal wall loss, lamination, crack and ovality. Intelligent pigs are sized close to inner diameter of pipelines, deployed through launcher and retrieved at receiver. Pipeline product is usually used to propel intelligent pig from the launcher to receiver trap. However, pressure, flow rate and velocity of pipeline product needs to be reviewed to ensure these parameters are within tool specification (Mokhatab et al, 2007). There are three main type of intelligent pigs, which are magnetic flux leakage, ultrasonic and geometry pigs.

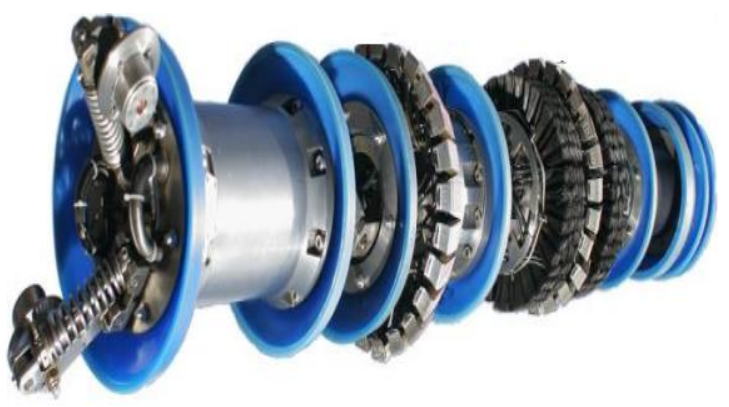

Figure 4: Magnetic flux leakage inspection tool (Palmer and Hennig, 2013).

The magnetic flux leakage tools (Figure 4) are fitted with several powerful magnets and induces magnetic flux leakage into pipe wall thickness as its travels through pipelines. This flux leakages are detected by sensors ridding on the tool body and the recorded magnetic flux data is analyzed and used to identify presence of internal and external metal volume loss (Kishawy and Gabber, 2010).

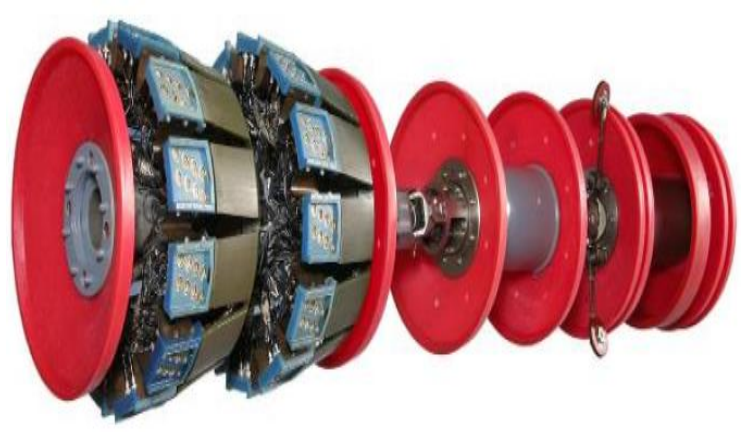

Figure 5: Ultrasonic inspection tool (Slaughter, 2012).
Secondly, the ultrasonic inspection tools (Figure 5) are fitted with several number of transducers and sensors that are arranged circumferentially around the body of the tool and ultrasonic waves are transmitted into the pipe wall at about $45^{\circ}$ and the return pulse echoes from back and front pipe walls are recorded by sensors. This recorded information is then analyzed and correlated with wall thickness losses from both internal and external walls (Sofferman, 2012; Costello et al, 2007).

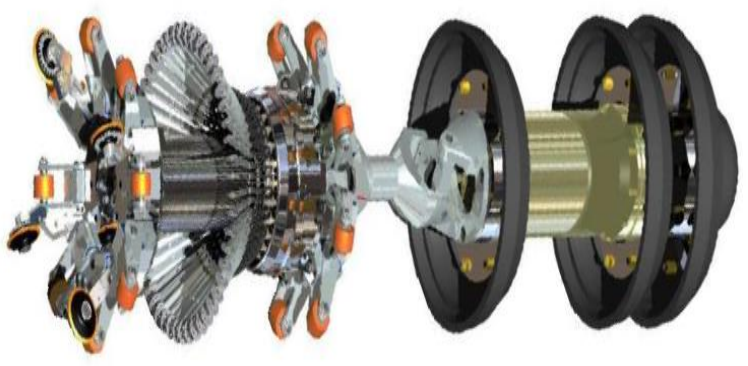

Figure 6: Geometry inspection tool (Baker Hughes, 2015).

Thirdly, the caliper pigs (Figure 6) measure and located dents or bore reduction and usually run to gauge pipelines prior to launching magnetic flux leakage or ultrasonic tools. However, performance of the smart pigs is affected by factors such as pipeline cleanness level, pig speed, specification of fluid presence in the pipeline and magnetic field or sound wave strengths, therefore, pipelines data including operating condition are evaluated for proper tool selection (Najafabadi et al, 2015). Additionally, there are non-intrusive and nondestructive examination (NDE) inspection techniques such as eddy current, magnetic particles, ultrasonic and radiographic that are hand-carried tools and mainly used for topsides corrosion measurement to compliment intelligent inspection. But the major disadvantages of the non-intrusive techniques are accessibility requirement and corrosion profiling that is based on point-by-point measurement (Boateng et al, 2013).

\section{CONCLUSION}

This paper has reviewed best practices of corrosion control and monitoring strategies used nowadays by the oil majors like Shell, Chevron, Total and ExxonMobil to monitor and control corrosions. Corrosion is a destructive attack on metallic materials. Reports from oil majors and field experiences showed that several networks of pipelines in Nigeria oil and gas industry have failed catastrophically in the last two decades. The reason is that a significant number of pipelines operate in corrosive environment and transport corrosive fluids.

However, corrosion attack on pipelines can be controlled with proper design of pipeline system, material selection, pipelines coating to serve as primary protection and installation of secondary protection system like cathodic protection. In addition to the controlled strategies, effective pipelines integrity plans which include monitoring flow parameters, dissolved gases in bulk water, performance 
evaluation of cathodic protection system and in-line inspection that provide information on corrosion profile and remaining wall thickness are necessary to protect and extend service life of pipelines. Pipelines integrity management which encompasses documentation of pipelines data, controlled strategies and inspection data guide owners of pipelines to determine inspection frequency, remaining life and failure prediction without risk of in-service failure.

\section{REFERENCES}

Agarwal, S., Kumar, S., Agarwal, M. and Kamal, M. (2015). Corrosion: A General Review, Internal Conference of Advance Research and Innovation, India, 181-183.

Ameh, E.S. and Ikpeseni, S.C. (2017). Pipelines Cathodic Protection Design Methodologies for Impressed Current and Sacrificial Anode System, Nigeria Journal of Technology, 36(4): 1072 - 1077.

Aroh, K.N., Ubong, I.U., Eze, C.L., Harry, I.M., UmoOtong, J.C. and Gobo, A.E. (2010). Oil Spill Incidents and Pipelines Vandalization in Nigeria: Impact on Public Health and Negation of Attainment of Millennium Development Goal - the Ishiague Example, Disaster Prevention and Management: An International Journal, 19(1): 70 - 87.

ASM (2014). Corrosion: Understanding the Basis, ASM International, Material Park, Ohio, USA

Baker Hughes (2015). Pipeline Management Inspection Services, Tool Data Specification sheet, Houston, Texas.

Beech, I. B. and Sunner, J. (2004). Biocorrosion towards Understanding Interactions between Biofilim and Metal, Current Opinion in Biotechnology, 15(3): 181-186.

Birkinshaw, P.; J. Soltis and D. Sandana. (2015). Operational Pigging - A Frontline Tool to Control Internal Corrosion of Pipelines. Pigging Products and Services Association Seminar and Workshop, (PPSA 2015), Aberdeen, UK, 1-9.

Boateng, A.; K. A. Danso and C. P. K. Dagadu. (2013). Non-Destructive Evaluation of Corrosion on Insulated Pipe using Double wall Radiographic Technique, Journal of chemistry and material research, 3 (4): 73 - 83.

Bushman, J. B. (2012). Corrosion and Cathodic Protection Theory, Bushman Associate Inc, Medina, Ohio.

Cai, J.; C. Li., X. Tang, F. Ayello, S. Richter and S. Nesic. (2012). Experimental Study of Water Welting in OilWater Two Phase Flow - Horizontal Flow of Model Oil, Chemical Engineering Science, 73: 334-344.

Costello, S. B.; D. N. Chapman, C. D. F. Roger and N. Metje. (2007). Underground Asset Location and Condition Assessment Technologies, Tunneling and Underground Space Technology, 22: $524-542$.

Diaz, E. (2002). Optimization of ICCP Systems to Minimize Electronic Signature, Boundary Elements XXIV, CA Brebbia, WIT Press, Ashurst Lodge, Southampton, UK.

DNV, (1993). Cathodic Protection Design, Recommended Practice B401, DNV Corporate Headquarter, Oslo, Norway.

DNV. (1994). Material Selection, Norsok Standard Design principle, M-DP-001, Norwegian Technology Centre .
Ezekiel, E. (2015). Introduction to Electrical Design for Cathodic Protection System, Article Review, unpublished Lecture Note, Ezekiel Enterprises, LLC.

Intetech Consultancy Ltd (2010). Corrosion and Selection of Materials for Carbon Capture and Storage, IEAGHG Programme, Technical Report.

Kehr, J. A.; S. Attaguile, M. Smith and M. Perez (2007). New Technology Helps Develop Coatings for High Operating Temperature Pipelines, NACE Corrosion Conference and Exhibition, Las Vegas, 1- 24.

Kishawy, H. A. and Gabbar, H. A. (2010). Review of pipeline Integrity Management Practices, International Journal of Pressure Vessels and Piping, 87(7): 373-380.

Kjellerup, B. V.; G. Gudmonsson, K. Sowers and P. H. Nielsen. (2006). Evaluation of Analytical Method for Determining the Distribution of Biofilm and Active Bacteria in a Commercial Heating System, Journal of Biofouling, 22: $133-139$.

Li, S. Y.; S. Jung, K. W. Parl, S. M. Lee and Y. G. Kim. (2007). Kinetic Study on Corrosion of Steel in Soil Environment Using Electrical Resistance Sensor Technics, Materials Chemistry and Physics, 103(1): 9-13.

Lim, G. (2013). Advancement in Spray Pig Application; Pigging Product and Service Association Seminar, T.D. Williamson, Inc, Norway.

M'hammed, O.; Z. Mourad, T. Omar, I. Rachid, B. Saida and D. Charif. (2014). AC Corrosion Induced by High Voltage Powerline on Cathodically Protected Pipeline. 2nd International Conference on Control, Engineering and Information Technology (CEIT-2014), 7: 22-26.

Manafi, Z.; M. Hashemi, M. Abdollahi and G. Olson. (2013). Bio-corrosion of Water Pipeline by SulphateReducing Bacteria in a Mining Environment. African Journal of Biotechnology, 12(46): $6504-6516$.

Manier. F.; R. F. Leta and F. F. Feliciano. (2014). Application of Anti-corrosive Techniques Compatibility with the Environmental to Engineers Education. American Journal of Environmental Engineering, 4(6):176 - 181.

Mathiazhaghan, A. (2010). Design and Programming of Cathodic Protection for Ship. International Journal of Chemical Engineering and Applications, 1(3): 217-221.

Mazraeh, A. A. and Alnaimi, F.B.I. (2015). MultiDiameter Pipeline Inspection Gauge for Long Distance Industrial Application. International Journal of Scientific and Engineering Research, 6(2): 646 - 650.

Miller, W. T. R.; S. Sutton and E. Werbros. (1990). Neural Networks for Control. MIT Press, Cambridge.

Mokhatab, S.; S. P. Santos and G. Lamberson. (2007). Pipeline System: Control and Integrity Management. Journal of Pipeline Engineering, 6 (4): 262 - 267.

Mosher, M. (2013). Managing Corrosion of Pipelines that Transport Crude Oils. NACE International, 52(5): 28 35 .

Murad, M. A. (2012). The Development of Structural Health Monitoring Procedures for the Structural Integrity and Maintenance Repair of Offshore Ageing Pipelines. 4th European-American Workshop on Reliability of NDE, UK.

NACE International (2007). Standard Practice for Control of External Corrosion on Underground or Submerged 
Metallic Piping system. National Association of Corrosion Engineers, Houston, Texas.

Najafabadi, M. A.; G. Fereyduni, H. Gholami and H. Kholghnik. (2015). Comparison and Verification of the Performance Specification of MFL Pigs and Field Inspection Based Error Propagation and Gaussian Distribution Method, International Journal of Engineering Innovation and Research, 4(3): $446-453$.

Nicholson, E. (2012). Corrosion Measurement in Electrochemical Protection, XII National Conference, Jurata, Poland: 95-104.

Nicholson, P. (2006). External Corrosion Direct Assessment, in Pipeline Rehabilitation and Maintenance, Article of Cathodic Technology Limited, Istanbul, Turkey, 17.

Oki, M.; A. A. Adediran and P. A. Anawe. (2015). Corrosion Monitoring in the Oil Pipeline Industry, Journal of Multidisciplinary Engineering Science and Technology, 2 (1): $299-302$.

Palmer, J. and Henning, T. (2013). Corrosion Growth Analysis - Case Study of MFL-UT Combined Inspection, 7th Pipeline Technology Conference, Lingen, Germany: 111-118.

Peabody, A. W. (2001). Control of Pipeline Corrosion, Second Edition, Pub. NACE International, Texas, USA.

Ramesh, S.; S. Rajeswari and S. Maruthamuthu. (2003). Effect of Inhibitors and Biocides on Corrosion Control of Mild Steel in Natural Aqueous Environment. Journal on Materials Letter, 57: 4547 - 4554.

Reinhart, M.F. (1975). Design for Corrosion Control of Potable Water Distribution System, National Technical Information Service, U.S. Department of Commerce.

Roberge, P.R. (2000). Handbook of Corrosion Engineering, McGraw-Hill PY, New York.

Romano, M.; M. Dabiri and A. Kehr. (2005). The ins and outs of Pipeline Coatings: Coating used to Protect Oil and Gas Pipelines, Journal of Protective Coatings and Linings Technology, 40 - 47.
Samimi, A. (2012). Use of Polyurethane Coating to Prevent Corrosion in Oil and Gas Pipelines Transfer. International Journal of Innovation and Applied Studies, 1(2): 186-193.

Samini A. and Zarinabadi, S. (2011). An Analysis of Polyethylene Coating Corrosion in Oil and Gas Pipelines. Journal of American Science, 7(1): 1032-1036.

Scott, P. J. B. (2004). Expert Consensus on MIC: Prevention and Monitoring. Material Performance 2004, 43: $50-54$.

Slaughter, M. (2012). Pipeline Inspection, Case study: Design Improvement on a New Generation UT-in Line Inspection Crack Tool. Pigging Products and Services Association Seminar (PPSA2012), Aberdeen, UK.

Smith, S.; J. Burd and S. Neville. (2010). Using Intelligent Pigs to Successfully Access Condition of your Pipe, News Article, available online at www.tdwilliamson.com/solutions/pipeline-pigging.

Sofferman, R. A. (2012). Physics and Principle of Ultrasound, in Ultrasound of the Thyroid and Parathyroid Glands. Springer.

Tezdogan, T. and Demirel, Y. K. (2014). An Overview of Marine Corrosion Protection with a Focus on Cathodic Protection and Coating. Journal of Brodagradnja (Shipbuilding), 65(2): $49-59$.

Varela, F.; M. Y. Tan and M. Forsyth. (2015). An Overview of Major Methods for Inspecting and Monitoring External Corrosion of Onshore Transportation Pipelines. Corrosion Engineering, Science and Technology, 50(3): 226 -235 .

Varela, H. A. and Quintero, L. K. H. (2011). Biocorrossion in Oil Recovery System, Prevention and Protection. An Update, Revista Tecnica de la facultad de Ingenieria Universidad del Zulia, 34(2): 123 -137.

Xu, L. and Xiaoyu, W. (2014). The Research of oil and Gas Pipelines Corrosion and Protection Technology. Journal of Advances in Petroleum Exploration and Development, 7(2): $102-105$. 